\title{
Fabrication of Triprolidine.HCI Transdermal Drug Delivery System and Pharmacokinetic Studies
}

\author{
Afzal Haq Asif ${ }^{1}$, Niranjan Puttaswamy Hodalur ${ }^{2}$, Nagaraja Sreeharsha ${ }^{3,4, *}$, Jagadeesh Gurupadayya \\ Hiremath $^{5}$, Keyur Shileshbhai Mistry ${ }^{6}$, Bandar E Al-Dhubiab ${ }^{3}$, Girish Meravanige ${ }^{2}$, Ranjith Kumar \\ Karnati ${ }^{7}$, Saleemulla Khan ${ }^{8}$, Muhammed Mubin ${ }^{9}$, Aiswarya Thelakkadan Chathoth ${ }^{9}$
}

1'Department of Pharmacy Practice, College of Clinical Pharmacy, King Faisal University, Al-Ahsa, SAUDI ARABIA.

2Department of Biomedical Sciences, College of Medicine, King Faisal University, Al-Ahsa, SAUDI ARABIA.

${ }^{3}$ Department of Pharmaceutical Sciences, College of Clinical Pharmacy, King Faisal University, Al-Ahsa, SAUDI ARABIA.

${ }^{4}$ Department of Pharmaceutics, Vidya Siri College of Pharmacy, Off Sarjapur Road, Bangalore, INDIA.

${ }^{5}$ Department of Pharmaceutics, PA College of Pharmacy, Mangalore, INDIA.

${ }^{6}$ Department of Pharmaceutics, KLE University, Belgaum, Karnataka, INDIA.

${ }^{7}$ Department of Chemistry, College of Science, King Faisal University, Hofuf, SAUDI ARABIA.

${ }^{8}$ Department of Pharmacognosy PA College of Pharmacy, Mangalore, INDIA.

${ }^{9}$ Department of Pharmaceutical Chemistry, PA College of Pharmacy, Mangalore, INDIA.

\begin{abstract}
The purpose was to examine and analyze the matrix system of Triprolidine $\cdot \mathrm{HCl}$ wth the selected polymer ethyl cellulose. We achieved in vitro permeation studies using Keshary Chien diffusion cells across guinea pig skin. Considering the success of permeation enhancers with differing concentrations to enhance the permeation rate. The performed the in vitro dissolution of the developed transdermal patches. The in vivo analysis was carried out on male albino rabbits the drug release was determined by high performance liquid chromatography. The significant high performance liquid chromatography retention time of triprolidine $\cdot \mathrm{HCl}$ was $4.0 \mathrm{~min}$. The limit of detection was $10 \mathrm{ng} / \mathrm{mL}$ and quantification limit of was $17 \mathrm{ng} / \mathrm{ml}$. The area under curve was found to be $646.39 \mathrm{ng} / \mathrm{ml} . \mathrm{hr}$ with the Kel was 0.0682 and Ka was 0.184 hour- 1 . The peak plasma concentration $24.54 \mathrm{ng} / \mathrm{ml}$ were produced in peak time of $8.58 \mathrm{hrs}$ with the half life of $10.16 \mathrm{hrs}$.
\end{abstract}

Key words: Matrix TDDS, Triprolidine $\cdot \mathrm{HCl}$, Ethyl cellulose, Pharmacokinetics.

\section{INTRODUCTION}

In the management of allergic hypersensitive reactions Triprolidine $\mathrm{HCl}$ is potent molecule and is provided in a conventional dosage form for a course of 3 to 4 times day depending upon the condition of the illness. Triprolidine $\mathrm{HCl}$, antihistamine, has been administered three to four times a day to treat allergic rhinitis, urticaria, and allergic drug reaction.

Drug has low oral bioavailability (4\%), lower biological half-life (4 to $6 \mathrm{hr}$ ), higher early pass metabolism and also a higher repetition of drug dosing, which reduces its therapeutic effect by oral route. It is absorbed from the intestinal tract and higher hepatic metabolism, therefore leading to constant administration of greater dosages to provide a beneficial drug level. Then, emphasizing efficient plasma concentration of a consistent distribution of a drug is recommended. The transdermal route is a further substitute to reach a steady plasma level that requires less frequent dosage administration. ${ }^{1-5}$ The investigation group studied on Triprolidine (converted salt to basic form) and prepared the transdermal drug release systems. Ethylene vinyl acetate (EVA) involves a rate controlling membrane with polyethylene glycol 400 as a solubilizer. Percent composition of vinyl acetate (VA) is ratecontrolling step for triprolidine diffusion or permeability coefficient reported. The citrate group plasticizers showed effective drug permeation contrasted to the phthalate
Submission Date: 14-07-2020; Revision Date: 23-08-2020; Accepted Date: 17-09-2020

DOI: 10.5530/ijper.54.3s.150 Correspondence: Nagaraja Sreeharsha Department of Pharmaceutical Sciences, College of Clinical Pharmacy, King Faisal University, Al-Ahsa, SAUDI ARABIA.

Phone: +96-653-548-5322

E-mail: sharsha@kfu.edu.sa

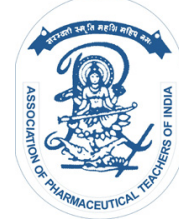

www.ijper.org 
groups mentioned. The same organize in separate applications formed poly (4-methyl-1-1-pentane (TPX) polymer as a rate controlling membrane and TPX transdermal matrix system comprising triprolidine. ${ }^{6-8}$ Drug permeation enhanced using alkyl citrate plasticizers. Another exploration formulation tested to study vascular permeability and drug permeability on mouse skin. Pharmacokinetic parameters performed using rodents. Their subjects demonstrated that triethyl citrate (TEC) employed as a plasticizer and penetration enhancer of polyethylene-2-oleyl ether (POE) enhanced permeation of drug across the skin. Progresses of pharmacokinetic specifications indicated that pharmacological action was increased 1.55 fold contrast to a limit group., ${ }^{9,10}$ However, considering to industrial point of view the synthesis or conversion of salt to basic is an additional process and stability. Moreover, the ethyl cellulose (EC) polymer is not attempted with triprolidine in the above explained studies of TDDS. The present work an attempt is been made to design and characterize the triprolidine $\mathrm{HCl}$ loaded transdermal matrix system. Ethyl cellulose (EC) is used as rate controlling polymer in TDDS because of its lipophilicity and insoluble in diffusion media. The EC is the best polymer in developing TDD systems consisting of insoluble and soluble active pharmaceutical ingredients. ${ }^{11}$ Another vital factor in TDDS preparation is plasticizer. It usually needs plasticizers in film forming systems to bring flexibility to the film and promote the tensile strength of the prepared film. As an example of plasticizer, dibutyl phthalate (DBP) different concentration was investigated in a report for evaluation of its effect on the drug diffusivity which is an integral component for generating the controlled release membranes or films. ${ }^{11}$ To enhance drug diffusion through the skin, permeation enhancers are usually used, which can enhance drug diffusion from the formulation or to skin thicknesses. For precedent, described that dimethyl sulfoxide (DMSO) is a dipolar aprotic solvent composed of sulfur compound a penetration enhancer it features three specific mechanisms of response on the cell membrane it promotes the enlargement and reduction of the lipoid layers, enhancing the fluidity of the lipophilic part of the barrier. It activates the development of transitory "water pores" in the cell membrane, causing the fluidity of the bilayer. DMSO can extract lipid molecules and break down the lipid layer in subcutaneous (SC). ${ }^{12-14}$ The fluidization of the stratum corneum of the lipids can be increased by using the surfactants (non ionic) lead to absorption of drug molecules. However, there are two processes by which it maintains the rate of transport using surfactants (nonionic) such as polysorbate- 80 and sorbitan monooleate-80. These surface active agents may cross through into the interstitial uptake of subcutaneous (SC) tissue, increase mutability, and solubilize and extract lipoid components. It associates and adheres to the keratin filaments, which stimulate the disruption within the corneocyte. ${ }^{15}$

\section{MATERIALS AND METHODS}

\section{Materials}

Triprolidine $\cdot \mathrm{HCl}$ was taken in as a gift sample from Pioneer laboratories (Indore, India), ethyl cellulose was obtained from Colorcon Asia Pvt Ltd (Goa, India), dimethyl sulfoxide, tween 80 and span 80 procured from Loba chemicals (Mumbai, India), backing layer $\left(3 \mathrm{M}^{\mathrm{TM}}\right.$ CoTran ${ }^{\mathrm{TM}} 9720$ polyethylene monolayer film), deliver liner $\left(3 \mathrm{M}^{\mathrm{TM}}\right.$ Scotchpak 1022 fluoropolymer coated polyester film) gifted from 3M Drug Delivery Systems (US).

\section{Preparation of a matrix of the transdermal patch}

In the present research work solvent casting reported method and modified according our laboratory conditions was adopted for preparing matrix transdermal patches. ${ }^{16}$ In that ethyl cellulose $4 \%$ and $6 \% \mathrm{w} / \mathrm{v}$ was dissolved in ethanol $(5 \mathrm{ml})$ with continuous intial stirring at $50 \mathrm{rpm}$ then follwed at higher speed of $250 \mathrm{rpm}$ on a magnetic stirrer, $40^{\circ} \mathrm{C}$ temperature was maintained. Next, triprolidine $\mathrm{HCl}$ was incorporated to the above polymeric solution and uniformly mixed with continuous stirring followed by addition of plasticizer and permeation enhancers were added individually, and made up the volume up to $10 \mathrm{ml}$ and further stirred properly on the magnetic stirred up to 20 minutes at $250 \mathrm{rpm}$. Clear solution transferred to the petridish containing backing layer $\left(3 \mathrm{M}^{\mathrm{TM}}\right.$ CoTran ${ }^{\mathrm{TM}}$ 9720 polyethylene monolayer film) and then dried up at room temperature for 24 hours for complete solvent evaporation via inverting the funnel on a petri dish. The transdermal patches were removed by using the sharp blade by inserting along the edges of the patch. The releasing liner on the polymer drug matrix with little pressure was applied manually. The flixible films were stored in the aluminiumexapanse and keep away from light in the cool place. ${ }^{16}$ It shows the composition of the matrix of transdermal patches in Table 1.

\section{DSC analysis}

DSC was established with the (Mettler-Toledo Star system). We investigated samples (1:1 ratio) and set in the confined aluminum berate under liquid nitrogen atmospheric condition. We inspected the formulations and physical blend mixtures (1:1 ratio) at $10^{\circ} \mathrm{C} / \mathrm{min}$ from 0 to $240^{\circ} \mathrm{C} .{ }^{17}$ 


\section{Physicochemical interpretation of transdermal patches}

The drug loaded polymeric patches $\left(4 \mathrm{~cm}^{2}\right)$ were conducted to pressure variation by individually examining each formulation. ${ }^{16,18,19}$ The mean weight and the standard deviation values were determined by weighing the individual films. The thicknesses of the drug-loaded $\left(4 \mathrm{~cm}^{2}\right)$ polymeric films were measured at 6 different pointsby means of digital calipers (Mitutoyo, Japan). We calculated the average and standard deviation of six readings for each batch of the drug-loaded films.

\section{Content Uniformity}

For each drug loaded transdermal patches of $4 \mathrm{~cm} 2$ sections from different lots were cut into short portions were dispersed $5 \mathrm{ml}$ of ethyl alcohol containing screw capped bottle solubilized and the solutions were filtered by 0.45 micron membrane filter to these samples made up the volume up to 100 with $\mathrm{pH}$ 7.2, phosphate buffer, the drug content uniformity analyzed utilizing a UV spectrophotometer at $230 \mathrm{~nm}$.

\section{Tensile strength}

To fold the number of times until either to break or to produce detectable cracks was noted for each examine as the persistence of the film. ${ }^{16}$ Tensile strength tests the force needed to fracture apart a film membrane. Tensile strength of the prepared filmswere measured by using a tensiometer (Erection and instrumentation Co., Ahmadabad, India). A $2 \mathrm{~cm}$ width and $7 \mathrm{~cm}$ length film was set between the lower and upper cell grips and the force later was tested on the upper grip until it broke the film. The applied force was recorded and the Young Modulus factor was imposed for each sample. The detailed calculated data were reported in Table 2.

\section{Folding endurance}

We studied the folding strength for the prepared films. A strip of patch $4 \mathrm{~cm} 2$ was cut and folded at the same place till it cracked. We carried the correct folding endurance out by the time at which no fracture of the films when folded the number of times of the films at the same place. ${ }^{17}$

\section{Moisture content}

The transdermal patch $4 \mathrm{~cm}^{2}$ was collected, weighed, and placed in a moistureapparatus kept at 68\% RH for 72 hours for stability. After 72 hours polymer patch was drawn out and weighed. The difference between the original and ultimate weight was computed as the percent moisture absorbed was determined. ${ }^{11,20}$

\begin{tabular}{|c|c|c|c|c|c|c|}
\hline \multicolumn{1}{|c|}{ Table 1: The composition of matrix type of transdermal patches. } \\
\hline Formulations & M1 & M2 & M3 & M4 & M5 & M6 \\
\hline Triprolidine HCL $(\% \mathrm{w} / \mathrm{v})$ & 0.04 & 0.04 & 0.04 & 0.04 & 0.04 & 0.04 \\
\hline Ethyl Cellulose $(\% \mathrm{w} / \mathrm{v})$ & 4 & 6 & 4 & 6 & 4 & 6 \\
\hline Ethanol & $10 \mathrm{~mL}$ & $10 \mathrm{~mL}$ & $10 \mathrm{~mL}$ & $10 \mathrm{~mL}$ & $10 \mathrm{~mL}$ & $10 \mathrm{~mL}$ \\
\hline Dibutyl Phthalate $(\% \mathrm{w} / \mathrm{v})$ & 2.66 & 4 & 2.66 & 4 & 2.66 & 4 \\
\hline DMSO (\%w/v) & 2 & 2 & - & - & - & - \\
\hline Tween 80 (\%w/v) & - & - & 1 & 1 & - & - \\
\hline Span 80 (\%w/v) & - & - & - & - & 1 & 1 \\
\hline
\end{tabular}

\begin{tabular}{|c|c|c|c|c|c|c|c|}
\hline FC $\neq$ & $\begin{array}{c}\text { Weight } \\
(\mathrm{mg} \pm \mathrm{SD}) \dagger\end{array}$ & $\begin{array}{l}\text { Thickness } \\
\text { (mm } \pm \text { SD)† }\end{array}$ & $\begin{array}{l}\text { Drug content } \\
\text { uniformity } \\
(\mathrm{mg} \pm \mathrm{SD}) \dagger\end{array}$ & $\begin{array}{l}\text { Tensile strength } \\
\left(\mathbf{k g} / \mathrm{mm}^{2} \pm \mathrm{SD}\right) \dagger\end{array}$ & $\begin{array}{c}\% \text { Elongation } \\
\pm \text { SD } †\end{array}$ & $\begin{array}{c}\text { Folding } \\
\text { endurance } \pm \\
\text { SD† }\end{array}$ & $\begin{array}{c}\% \text { Moisture } \\
\text { content } \\
\pm \text { SD } †\end{array}$ \\
\hline M1 & $32.2 \pm 0.006$ & $0.09 \pm 0.01$ & $3.8 \pm 0.021$ & $1.960 \pm 0.04$ & $0.68 \pm 0.001$ & $334 \pm 7$ & $1.9 \pm 0.02$ \\
\hline M2 & $33.4 \pm 0.015$ & $0.11 \pm 0.04$ & $3.8 \pm 0.013$ & $1.276 \pm 0.03$ & $0.46 \pm 0.007$ & $320 \pm 5$ & $2.4 \pm 0.01$ \\
\hline M3 & $30.8 \pm 0.010$ & $0.08 \pm 0.03$ & $3.7 \pm 0.04$ & $1.449 \pm 0.01$ & $0.52 \pm 0.004$ & $328 \pm 1$ & $2.1 \pm 0.04$ \\
\hline M4 & $40.1 \pm 0.015$ & $0.09 \pm 0.02$ & $3.6 \pm 0.032$ & $1.556 \pm 0.02$ & $0.46 \pm 0.003$ & $312 \pm 4$ & $2.8 \pm 0.01$ \\
\hline M5 & $40.2 \pm 0.012$ & $0.08 \pm 0.01$ & $3.5 \pm 0.012$ & $1.040 \pm 0.03$ & $0.44 \pm 0.007$ & $329 \pm 3$ & $2.5 \pm 0.03$ \\
\hline M6 & $47.5 \pm 0.010$ & $0.09 \pm 0.04$ & $3.6 \pm 0.025$ & $1.640 \pm 0.04$ & $0.56 \pm 0.009$ & $315 \pm 2$ & $2.9 \pm 0.01$ \\
\hline
\end{tabular}




\section{In vitro drug release study}

We studied formulations in vitro drug dissolution for the period of 24 hours. The study was conducted using USP type II apparatus using experimental patch on the glass slide by using $500 \mathrm{ml}$ phosphate buffer $\mathrm{pH} 7.2$ as a dissolution medium.

\section{In vitro drug skin permeation studies}

The investigation was accepted by the institutional ethical committee. Domestic guinea pig were massacred by cervical disarticulation and back skin was discharged. Then, disposing of the epidermis hairs and the fats of subcutaneous tissues and cleaned the skin kept overnight in connect with the receptor phasecontaining $\mathrm{pH}$ 7.2, phosphate buffer. ${ }^{18}$ We carried the in vitro drug permeability study out using fabricated, Keshary Chien diffusion cells. The guinea pigupper posterior side of skin was fixedamong the donor and recipient sections. The donor compartment containing $5 \mathrm{ml}$ of drug $(4 \mathrm{mg})$ solution with optimized and regulated, a particular concentration of permeation enhancers, dimethyl sulfoxide (DMSO) (2\% v/v), tween 80 (1\% $\mathrm{v} / \mathrm{v})$, span $80(1 \% \mathrm{v} / \mathrm{v})$ individually and the receptor compartment containing $50 \mathrm{ml}$ of phosphate buffer $\mathrm{pH}$ 7.2. The receptor phase of the temperature was kept constant at $37 \pm 1^{\circ} \mathrm{C}$ during study. The $1 \mathrm{~mL}$ of sample was taken at an fixed duration of time and replaced the sample volume phosphate buffer $\mathrm{pH} 7.237 \pm 1^{\circ} \mathrm{C}$ to the diffusion cells. The presence of the drug substance in the samples was determined at $230 \mathrm{~nm}$ using UV-Visible spectrophotometer. The flux was calculated using equation 1. $\Delta \mathrm{Q}_{\mathrm{t} .}{ }^{18,21}$ Where, $\Delta \mathrm{Q}_{\mathrm{t}}=$ difference between cumulative drug release, $S$ : Surface area and dt:time interval.

\section{Quantitative assay of triprolidine $\cdot \mathrm{HCl}$ in plasma}

The assay of triprolidine. $\mathrm{HCl}$ by a significant approach was worked out by operating by high pressure liquid chromatography (HPLC) as previously dipicted methods and altered. ${ }^{6-10,22,23}$ For the estimate of triprolidine $\mathrm{HCl}$ in plasma was analyzed by developed HPLC system using a C-18, $250 \times 4.6 \mathrm{~mm}$ column (Phenomenex). It accomplished the HPLC apparatus with an SPD-10A UV-Vis detector, LD-10AD pump, and a C-R7A plus integrator from Shimadzu-Japan. The mobile phase 20:80 v/v mixture of isopropyl alcohol and $0.1 \mathrm{M}$ phosphate buffer $\mathrm{pH} 2.0$ was used. The flow rate of the mobile phase was operated at 0.9 $\mathrm{ml} / \mathrm{min}$. The various concentrations of drug solutions differ from 10 to $1000 \mathrm{ng}$ were in dispersed in $1 \mathrm{ml}$ of fresh blood (heparinized epindroff tube), the samples were centerfused for a duration of 15 minutes and collected the plasma. For these plasma samples $1 \mathrm{ml}$ of dichloromethane (DCM) was added further centrifuged for 15 minutes and extracted the drug, the supernatant was received and continued evaporation for 6 hours. After complete evaporation DCM the freshly prepared $1 \mathrm{~mL}$ mobile phase was added filtered using 0.22 micron membrane filter, injected into the HPLC column. The column pressure differed from 80 to $85 \mathrm{kgf} /$ $\mathrm{cm}^{2}$. The eluent was determined by a UV detector at $229 \mathrm{~nm}$, and the data were obtained and interpreted with the software Spincotech station. A simple linear relationship was recognized in plasma among the height area of triprolidine. $\mathrm{HCl}$ and its concentrations with a good correlation coefficient ( $\mathrm{r}=0.9881$ ). The method was accurate (intra and inter) day change was detected to be less than 95-101\%) and proper (mean revival was $99.9 \%$ ). The standard curve, made as related above, was referred for estimating triprolidine $\mathrm{HCl}$ in the selected formulation M1. The method in this examine for the analysis of triprolidine $\mathrm{HCl}$ showed excellent responsive with specific. Outlining the plasma concentration vs time was linear with a good correlation coefficient.

\section{In vivo studies}

We have used rabbits for the estimation of transdermal patch containing a drug. ${ }^{6,9,10}$ The protocol for the investigation in animals was supported by the institutional ethical committee. The male albino rabbits $(n=6)$ were procured from central animal house, rabbits having weight $2.5-3.0 \mathrm{Kg}$ were selected for the in vivo studies. The rabbits were resided according to the laboratory guide lines. The treatment group rabbits were anaesthetized by applying $25 \% \mathrm{v} / \mathrm{v}$ ethyl carbamate physiological saline $(4 \mathrm{ml} / \mathrm{kg})$. The back skin of the rabbits was cleaned and the hairs were removed by an electric clipper. The abdominal part of the rabbits was shaved 12 hours before experiment started and disinfected with a rectified spirit. After 12 hours acclimatization, triprolidine $\mathrm{HCl}$ loaded patch $(0.7 \mathrm{mg} / \mathrm{kg}$, the dose) for the rabbits was established based on the weight of the rabbits according to the surface area ratio was administered to abdomen skin of rabbits and with constant interval from the marginal ear vein $1 \mathrm{ml}$ of blood was collected for the analysis of presence of drug. At defined interval of time 2, 4, 6, 8, 10, 12 and 24 hours the blood samples were collected at after transdermal administration in to heparinized epindroff tube and drug was extracted by adding 0.9 $\mathrm{ml}$ of dichloromethane, centrifuged at $10000 \mathrm{rpm}$. The clear supernatant solution was collected, evaporated under a flow of fluid nitrogen. After complete dispersal of DCM, the prepared mobile phase was included, and 
$20 \mu \mathrm{l}$ was introduce to $\mathrm{HPLC}$. The triprolidine $\mathrm{HCl}$ content determined by using calibration curve (slope0.2628 and $\mathrm{r} 2$ value-0.9881).

\section{Primary skin irritancy studies}

The initial skin inflammation subjects were performed on male albino rabbits $(n=4)$ weighing about 2.5$3.0 \mathrm{~kg}$ of either sex having 24 months of age. The animals were housed properly hosed under controlled temperature and light condition and fed with laboratory diet with water ad libitum. The rabbits abdominal region was cleaned and hairs were removed using an electric clipper. After 12 acclimatization the abdominal regions disinfected with a rectified spirit. The freshly prepared formulation was applied to the skin and protected using adhesive tape. The standard inflammation causing agent $(0.8 \% \mathrm{v} / \mathrm{v}$ of formaldehyde) was tested to compare the observation purpose. The observation of test samples showed after 7 days duration no sign of erythematic or odema. ${ }^{18}$

\section{RESULTS AND DISCUSSION}

\section{Preparation of matrix type of transdermal patch}

In the present application the matrix system containing triprolidine $\mathrm{HCl}$ was formulated for controlled release of drug in the treatment of allergic rhinitis and an attempt has been conducted to formulate patches to avoid first pass metabolism, to continue the action of drug, to reduce dosing frequency and to improve patient consent. The formulations contained of backing layer, delivering a liner, drug reservoir comprise ethyl cellulose, dibutyl phthalate, ethanol and permeation enhancers DMSO, tween 80 and span 80 . We well produced this system with the model drug triprolidine $\mathrm{HCl}$. All the polymers utilized for the fabrication of the transdermal technique produced suitable film-set properties. EC films were thin, able to bend without breaking, smooth and translucent. The approach used for preparation the patches was found to be appropriate method.

\section{Permeability studies}

The transdermal permeation of the drug affects partitioning and transporting the drug through the stratum corneum and epidermis. Hence, permeation enhancers are used to enhance the permeation through these layers by increasing the permeation coefficient of the drug, by altering the physicochemical properties of drug. The permeability study of triprolidine $\cdot \mathrm{HCl}$ was conducted with different permeation enhancers like DMSO, tween 80 and span 80 by using guinea pig skin (Figure 1). DMSO gave best improvement amongst them with the flux rate of $0.155 \mathrm{mg} / \mathrm{cm}^{2} / \mathrm{hr}$ and span 80 also showed increased permeation with the flux rate of $0.146 \mathrm{mg} / \mathrm{cm}^{2} / \mathrm{hr}$ but to a slighter amount correlated with DMSO (Figure 2). The obtained flux rates from three distinct penetration enhancers with distinct concentrations. The tween 80 and span 80 indicated reduction in drug partition in animal skinby DMSO, because of their slighter fluidization of the bilayer lipids in skin. ${ }^{12}$ Hence, DMSO was well taken in the progress of transdermal patches.

\section{Differential scanning calorimetry (DSC)}

The DSC experiments to investigate the prospect of any substantial interface between the drug and substances and crystal studies. The thermal nature of pure triprolidine $\mathrm{HCl}$ and physical blends were examined. Figure 3, presents the DSC study of pure triprolidine $\cdot \mathrm{HCl}$ produced a sharp endothermic peak at $114.92^{\circ} \mathrm{C}$. The DSC evaluation of the physical blend of the triprolidine $\cdot \mathrm{HCl}$ and polymers noted insignificant shifts in the melting end of triprolidine $\mathrm{HCl}$ in the mixtures. The endothermic peak of ethyl cellulose alone reached peak at $233.58^{\circ} \mathrm{C}$. The physical blend of triprolidine. $\mathrm{HCl}$ and ethyl cellulose had two endothermic peaks at $112.56^{\circ} \mathrm{C}^{1}$ and $230.88^{\circ} \mathrm{C}$. The DSC thermogram of optimized production M1 appeared sharp and compressed polymeric endothermic characteristic peak at $232.89^{\circ} \mathrm{C}$. The DSC study of pure triprolidine $\cdot \mathrm{HCl}$ obtained an intense endothermic peak that displayed the crystallinity of the drug. The DSC studies of the physical mixtures of the drug and polymers produced slight changes in the melting stage of triprolidine $\mathrm{HCl}$ in the polymer's behavior mixtures. The physical blend of triprolidine $\mathrm{HCl}$ and ethyl cellulose showed sharp endothermic peaks because of crystallinity and thermogram further acknowledged that there is no physicochemical effect between the drug and the polymer. The DSC thermogram of optimized formulation M1 drug peak was disappeared because of a crystalline nature of the drug was turned to amorphous, another justification for this event is the organic solvent process operated in the formulation.

\section{Physicochemical interpretation of patches}

The weights varied between $32.2 \pm 0.006$ to $47.5 \pm 0.010$ $\mathrm{mg}$ because of the excipients combination, which shows up those distinct quantities patch weights were almost identical. Among them the influence of developed formulation M1 turned up to be $32.2 \pm 0.006 \mathrm{mg}$. The dimensions (thickness) of patches varied between $0.08 \pm 0.01$ to $0.1 \pm 0.04 \mathrm{~mm}$. We found the thickness of optimized formulation M1 to be $0.09 \pm 0.01 \mathrm{~mm}$. The 
drug content conformity for the all formulations $(n=6)$ was tested by selecting each patch from different three batches and was found between $3.5 \pm 0.012$ to $3.9 \pm 0.023$ $\mathrm{mg}$.The tensile strength was tested by the altered apparatus and was found to be between $1.040 \pm 0.03$ to $1.960 \pm 0.04 \mathrm{~kg} / \mathrm{mm}^{2}$. The tensile strength was found to be $1.960 \pm 0.04 \mathrm{~kg} / \mathrm{mm}^{2}$. The percentage elongation was found to be between $0.44 \pm 0.007$ to $0.68 \pm 0.001$. From the proceeds formulation M1 provided more percent elongation and tensile strength. Folding endurance was found to be in the range between $312 \pm 4$ to $334 \pm 7$ which noted that the patches would not crack and would hold their integrity with general skin folding when employed. We found moisture content in the range between $1.9 \pm 0.02$ to $2.9 \pm 0.01$. It indicates the obtained appears in Table. 2. Formulation M1 showed maximum tensile strength, percent elongation, and folding ability as contrasted to alternative formulations. The drug content equality in the formulations noted further results with negligible changes, which affirmed accuracy and precision of the employed manufacture process. The results of the percentage moisture content proved that the increase in the proportion of hydrophilic polymer was relative to the percentage wetness (moisture) content elevation of the films. The percentage wetness (moisture)subject of the prepared formulations was low, which could support the formulations continued in stable condition and good physical strength during long-term storage. ${ }^{16}$ The percentage wetness (moisture) uptake of the formulations was near decline, which could prevent the formulations from microbial associations and with a small amount of weightiness. ${ }^{11}$

\section{In vitro drug release study}

We subjected matrix type of patches to in vitro drug release study without rate limiting membrane with two particular concentrations of ethyl cellulose $(4 \%$ and $6 \% \mathrm{w} / \mathrm{v})$. The percentage cumulative drug release for formulations M1-M6 was formed to be $98.47 \pm 0.20$, $94.58 \pm 0.02,87.71 \pm 0.19,86.901 \pm 0.30,89.66 \pm 0.23$ and $88.56 \pm 0.25$ for the duration of 24 hours investigation (Table 3). The M1 formulation showed higher drug release and controlled release for 24 hours. The release data indicated that by increasing the polymer concentration results showedreduced in the drug release.

\section{In vitro drug permeation study from guinea pig skin}

The control mechanism of drug release from the transdermal patches is controlled by the chemical properties of the drug, polymers and delivery form. The partition coefficient of the drug subjects can be except similar results in vivo performance of drug containing delivery form. In this investigation, varied formulations when conducted for in vitro permeation study, a diversity of triprolidine $\mathrm{HCl}$ release pattern was recognized from animal skin studies. Matrix formulations comprising different permeation enhancers such as DMSO, tween 80 and span 80 showed increase the drug partitionagainst the guinea pig skin.In vitro drug permeation research was carried out for all the formulations $(n=6)$ by utilizing

\begin{tabular}{|c|c|c|c|}
\hline Samples & $\begin{array}{c}\text { Flux } \\
\text { (mg/sq.cm/h) } \\
\text { with } \\
\pm \text { SD* }^{*}\end{array}$ & $\begin{array}{c}\text { Pharmacokinetic } \\
\text { parameters }\end{array}$ & $\begin{array}{l}\text { Pharmacokinetic } \\
\text { values } \pm S D^{*}\end{array}$ \\
\hline Pure drug & $0.149 \pm 0.046$ & AUC (ng/ml.hr) & $646.39 \pm 125$ \\
\hline $\begin{array}{l}\text { Tween } 80 \\
(1 \% \mathrm{w} / \mathrm{v})\end{array}$ & $0.155 \pm 0.023$ & $\mathrm{C}_{\max }(\mathrm{ng} / \mathrm{ml})$ & $24.54 \pm 6.56$ \\
\hline $\begin{array}{l}\text { Span } 80 \\
(1 \% \mathrm{w} / \mathrm{v})\end{array}$ & $0.153 \pm 0.047$ & $T_{\max }$ (hours) & $8.58 \pm 0.130$ \\
\hline $\begin{array}{l}\text { DMSO } \\
(1 \% \mathrm{w} / \mathrm{v})\end{array}$ & $0.152 \pm 0.056$ & $\mathrm{~K}_{\text {el }}\left(\right.$ hours $\left.^{-1}\right)$ & $0.068 \pm 0.012$ \\
\hline \multirow[t]{2}{*}{$\begin{array}{l}\text { Tween } 20 \\
(1 \% \mathrm{w} / \mathrm{v})\end{array}$} & $0.150 \pm 0.024$ & $\mathrm{~K}_{\mathrm{a}}\left(\right.$ hours $\left.^{-1}\right)$ & $0.184 \pm 0.015$ \\
\hline & & $T_{1 / 2}$ (hours) & $10.16 \pm 1.19$ \\
\hline
\end{tabular}

*All values are expressed as mean $\pm S D(n=4)$. M1 is the best matrix transdermal patch selected for the in vivo studies. $\mathrm{C}_{\max }$ indicates maximum concentration; $\mathrm{T}_{\text {max }}$ time of maximum concentration; $\mathrm{K}_{\mathrm{e}^{\prime}}$ elimination rate constant; $\mathrm{K}_{\mathrm{a}^{\prime}}$ absorption rate constant, $\mathrm{AUC}$, area under the plasma concentration-time curve; $\mathrm{t}_{1 / 2^{\prime}}$ elimination half-life. 


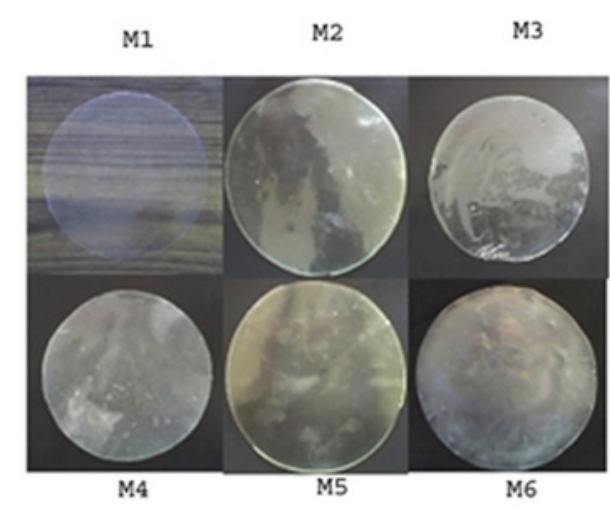

Figure 1. Typical formulations pictures of Triprolidine $\cdot \mathrm{HCl}$ loaded transdermal matrix delivery systems (M1-M6).

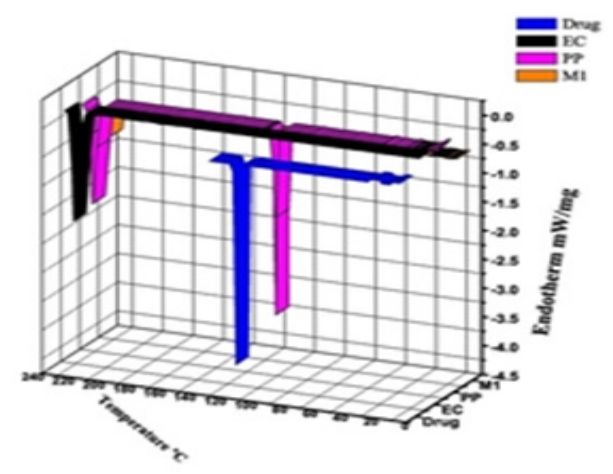

Figure 2. DSC thermogram of Drug (-), Ethyl cellulose (EC) (-), physical mixture (-)and M1 (-).

guinea pig skin using Keshary Chien diffusion cell with an actual surface area of $3.14 \mathrm{~cm}^{2}$. The cumulative amounts of drug penetrated from the formulations M1-M6 were established to be $83.654 \pm 1.238,82.906 \pm 0.120$, $81.194 \pm 1.318, \quad 80.161 \pm 0.837, \quad 79.253 \pm 1.451$ and $77.897 \pm 1.442$ up to 24 hours, respectively (Table 4 ). The investigated drug permeation data indicated that the incorporated DMSO as a permeation enhancer in formulation M1 showed good drug permeation when contrasted to alternative enhancer's tween 80 and span 80. The results proved that the lipophilic nature of the enhancer influenced cutaneous barrier impairment. The existence of surfactant in the patches further increased the drug partition coefficient time only to a slighter extent.

\section{In vivo investigations}

The triprolidine $\mathrm{HCl}$ determination was presented by high performance liquid chromatography. The retention time of triprolidine. $\mathrm{HCl}$ was $4.0 \mathrm{~min}$. The findinglowest concentration was $10 \mathrm{ng} / \mathrm{mL}$ and lowest quantification was $17 \mathrm{ng} / \mathrm{ml}$. The method reveled that a good straight

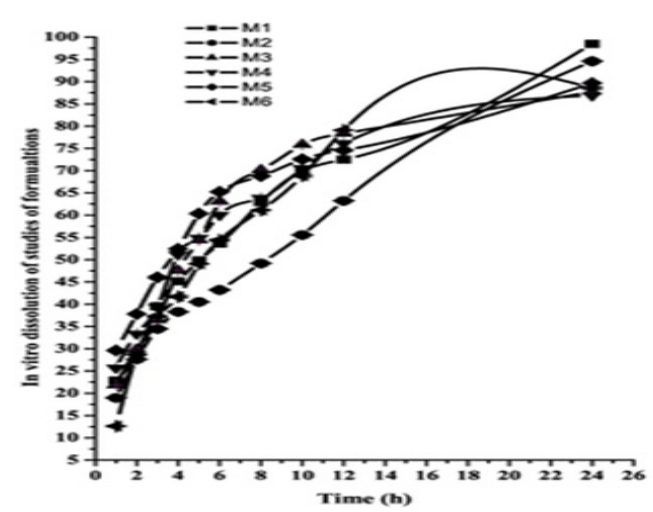

Figure 3. In vitro dissolution studies of formulations, M1 (ロ),

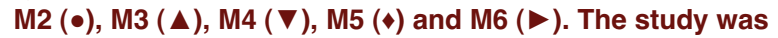
conducted by using USP type II apparatus, phosphate buffer pH 7.2 as a dissolution medium.

line against the area versus concentration range of $10-1000 \mathrm{ng} / \mathrm{mL}$.

The equation describe the standard curve is $\mathrm{y}=$ $0.2628 x$, with a mean correlating coefficient was 0.9881 . Triprolidine $\mathrm{HCl}$ was extracted from the plasma using DCM solvent system results showed that the recovery range of drug was found to $95-101 \%$. We achieved comparable results of triprolidineas recorded by separate investigations. ${ }^{6-8}$ The area under curve was found to be $646.39 \mathrm{ng} / \mathrm{ml} . \mathrm{hr}$ with the $\mathrm{K}_{\mathrm{el}}$ was 0.0682 and $\mathrm{K}_{\mathrm{a}}$ was 0.184 hour $^{-1}$. The peak plasma concentration 24.54 $\mathrm{ng} / \mathrm{ml}$ were achieved in peak time of 8.58 hours with the half life of 10.16 hours. In vivo investigations were carried out adopting rabbit as an animal model with the optimized formulation M1. The received results proved that the substantial concentration of the drug was reached with 24 hours function of the patch and the drug continue steadily in the blood of the rabbit up to 24 hours.

\section{Primary skin irritancy studies}

We have organized primary skin irritancy research on albino rabbits with the optimized formulation M1 which produced no sign of allergic reactions on the skin of rabbits after 7 days.

\section{CONCLUSIONS}

In the present investigation, it has made an attempt to establish transdermal matrix system of triprolidine $\cdot \mathrm{HCl}$ for controlled release of the drug as a one day remedy in the treatment of allergic rhinitis successfully. Transdermal matrix system was well produced by practicing ethyl cellulose containing triprolidine $\mathrm{HCl}$ as a model drug prepared by solvent casting method for the controlled release of drug. The characterization 
concluded that formulation M1 was found to be an enhanced formulation. The above consideration noted that prospect of forming a transdermal drug delivery system for triprolidine. $\mathrm{HCl}$ which will be further efficacious and adequate than the current dosage forms of triprolidine $\mathrm{HCl}$ and it could be a drug delivery of decision for one day analysis in the treatment of particular allergies.

\section{CONFLICTS OF INTEREST}

All the authors declares that there is no conflicts of interest regarding the publication of this research paper.

\section{Authors' Contributions:}

All authors performed experiment, performed analysis, interpreted results, writing, and revising the paper, gave approval for the final version submitted for publication. Agree to be accountable for all aspects of this work.

\section{ACKNOWLEDGMENTS}

This work was supported by Deanship of Scientific Research (DSR). King Faisal University (KFU). Al-Ahsa, Saudi Arabia (Grant No: 180119).

\section{ABBREVIATIONS}

EVA: Ethylene vinyl acetate; VA: Vinyl acetate; TPX: Poly (4-methyl-1-1-pentane; TEC:Triethyl citrate; POE: Polyethylene-2-oleyl ether; EC: Ethyl cellulose; DBP: Dibutyl phthalate; DMSO: Dimethyl sulfoxide; SC:Subcutaneous

\section{REFERENCES}

1. Ali SM, Asmat F. Spectroscopic Study on Interaction of $\beta$-Cyclodextrin with Triprolidine Hydrochloride. Chinese Journal of Chemistry. 2006;24(5):665-8. https://doi.org/10.1002/cjoc.200690127.

2. Dev R, Kumar A, Pathak K. Solubility-modulated asymmetric membrane tablets of triprolidine hydrochloride: Statistical optimization and evaluation. AAPS Pharm Sci Tech. 2012;13(1):174-83.doi: 10.1208/s12249-011-9738-3

3. Jewell RT. Drugs and Lactation Database (Lact Med). United States, National Library of Medicine (US). 2007.

4. Mustafizur M, Sultana R, Khan R. Binding of triprolidine hydrochloride to bovine serum albumin: Estimation of binding parameters and characterization of binding sites. Turkish Journal of Pharmceutical Sciences. 2013;10(1):4956.

5. Yasmeen S. Biophysical insight into the binding of triprolidine hydrochloride to human serum albumin: Calorimetric, spectroscopy and molecular docking approaches. Journal of Molecular Liquids. 2017;233:55-63. https://doi. org/10.1016/S0378-5173(01)00960-7.
6. Shin SC, Choi JS. Enhanced bioavailability of triprolidine from the transdermal TPX matrix system in rabbits. International Journal of Pharmaceutics. 2002;234(1-2):67-73. https://doi.org/10.1016/j.ejpb.2005.03.010.

7. Shin SC, Kim J, Yoon MK, Oh IJ, Choi JS. Transdermal delivery of triprolidine using TPX polymer membrane. International Journal of Pharmaceutics. 2002;235(1-2):141-7. https://doi.org/10.1016/s0378-5173(01)00996-6.

8. Shin SC, Lee HJ. Controlled release of triprolidine using ethylene-vinyl acetate membrane and matrix systems. European Journal of Pharmaceutics and Biopharmaceutics. 2002;54(2):201-6. https://doi.org/10.1016/S09396411(02)00051-6.

9. Shin SC, Choi JS. Antihistamine effects of triprolidine from the transdermal administration of the TPX matrix in rats. Archives of Pharmacal Research. 2005;28(1):111-4. https:// doi: 10.1007/bf02975145.

10. Shin SC, Choi JS. Enhanced efficacy of triprolidine by transdermal application of the EVA matrix system in rabbits and rats. European Journal of Pharmaceutics and Biopharmaceutics. 2005;61(1-2):14-9. https:// doi:10.1016/j.ejpb.2005.03.010.

11. Idrees A, Rahman NU, Javaid Z, Kashif M, Aslam I, Abbas K, et al. (2014). In vitro evaluation of transdermal patches of flurbiprofen with ethyl cellulose. Acta Poloniae Pharmaceutica Drug Research. 2005;71(2):287-95.

12. Barry BW, Bennett SL. Effect of penetration enhancers on the permeation of mannitol, hydrocortisone and progesterone through human skin. Journal of Pharmacy and Pharmacology. 1987;39(7):535-46. https:// doi:10.1111/j.2042-7158.1987.tb03173.x.

13. Gurtovenko AA, Anwar J. Modulating the structure and properties of cell membranes: the molecular mechanism of action of dimethyl sulfoxide. The Journal of Physical Chemistry B. 2007;111(35):10453-60. https:// doi:10.1021/jp073113e.

14. Williams AC, Barry BW. Penetration enhancers. Advanced Drug Delivery Reviews. 2012;64:128-37. https:// doi:10.1016/j.addr.2003.10.025.

15. Pandey A, Mittal A, Chauhan N, Alam S. Role of surfactants as penetration enhancer in transdermal drug delivery system. Molecular Pharmaceutics and Organic Process Research. 2014;2(113):2-7. http//doi:10.4172/23299053.1000113.

16. Kusum DV, Saisivam S, Maria GR, Deepti PU. Design and evaluation of matrix diffusion controlled transdermal patches of verapamil hydrochloride. Drug Development and Industrial Pharmacy. 2003;29(5):495-503. http// doi:10.1081/ddc-120018638.

17. Mutalik S, Udupa N. Formulation development, in vitro and in vivo evaluation of membrane controlled transdermal systems of glibenclamide. J Pharm Pharm Sci. 2005;8(1):26-38.

18. Tanwar Y, Chauhan C, Sharma A. Development and evaluation of carvedilol transdermal patches. Acta Pharmaceutica. 2007;57(2):151-9. http// doi:10.2478/v10007-007-0012-x.

19. Ubaidulla U, Reddy MV, Ruckmani K, Ahmad FJ, Khar RK. Transdermal therapeutic system of carvedilol: Effect of hydrophilic and hydrophobic matrix on in vitro and in vivo characteristics. AAPS Pharm Sci Tech. 2007;8(1):E1320. http//doi: 10.1208/pt0801002.

20. Baviskar DT, Parik VB, Jain DJ. Development of Matrix-type transdermal delivery of lornoxicam: in vitro evaluation and pharmacodynamic and pharmacokinetic studies in albino rats. PDA Journal of Pharmaceutical Science and Technology. 2013;67(1):9-22. http// doi: 10.5731/pdajpst.2013.00898.

21. Satturwar PM, Fulzele SV, Dorle AK. Evaluation of polymerized rosin for the formulation and development of transdermal drug delivery system: A technical note. AAPS Pharm Sci Tech. 2005;6(4):E649-54. http// doi: 10.1208/ pt060481.

22. Benezra SA, Yang $\mathrm{CH}$. Triprolidine hydrochloride. In Analytical Profiles of Drug Substances. 1979;8:509-28. Academic Press. https://doi.org/10.1016/ S0099-5428(08)60127-6.

23. Shah VP. The history of bioanalytical method validation and regulation: evolution of a guidance document on bioanalytical methods validation. The AAPS Journal. 2007;9(1):E43. https:// doi: 10.1208/aapsj0901005. 


\section{PICTORIAL ABSTRACT}

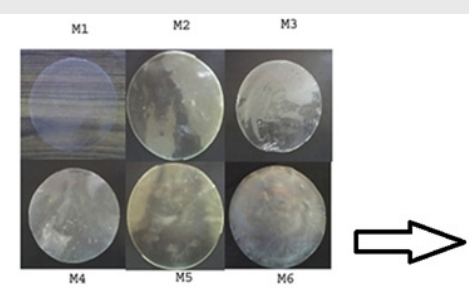

Triprolidine $\mathrm{HCl}$ loaded transdermal

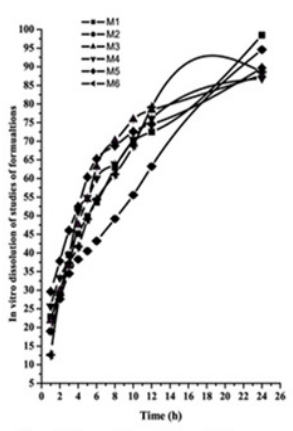

In vitro dissolution studies of formulations

\section{SUMMARY}

In the present study progressed and produced the matrix and reservoir systems containing triprolidine $\mathrm{HCl}$ as a model for controlled release of drug in the treatment of allergic rhinitis and an undertaking has been made to develop patches to avoid first pass metabolism, to prolong the action of the drug, to reduce dosing frequency, to increase patient compliance. From the results we can anticipate that the formulation M1 shows triprolidine $\mathrm{HCl}$ drug released up to $24 \mathrm{hrs}$.

\section{About Authors}

Dr. Sree Harsha received his (ranked top 5) Master of Pharmacy Degree and subsequently earned a doctorate in Pharmaceutics from Rajiv Gandhi University of Health Sciences, Bangalore, India in 2006. He came to King Faisal University in 2007 as an assistant professor in the Department of Pharmaceutical Sciences, bringing with him several years' worth of teaching experience in fundamentals of pharmaceutics and drug delivery systems. He was actively participated in Accreditation Council of Pharmacy Education (ACPE) and Canadian Council for the Accreditation of Pharmacy Programs (CCAPP). His primary area of focus is pharmaceutical technology and novel/ targeted drug delivery systems. For this research, he received grants (32 number) from Deanship of Scientific research, King Faisal University. The author contributed so far to 86 peer-reviewed full papers on a variety of topics in lung targeting, topical drug delivery and mucoadhesive drug delivery systems, He has contributed in writing a book chapter titled "Targeted Drug Delivery System" and "Microspheres" in Textbook of Industrial Pharmacy, Publisher-Orient Longman Private Ltd. In addition, he is an Ad-hoc reviewer for scientific journals. He has attended many seminars and Workshop both national and international on Pharmaceutical Technology and Public health issues.

Cite this article: Asif AH, Hodalur NP, Sreeharsha N, Hiremath JG, Mistry KS, Al-Dhubiab BE, et al. Fabrication of Triprolidine $\cdot \mathrm{HCl}$ Transdermal Drug Delivery System and Pharmacokinetic Studies. Indian $\mathrm{J}$ of Pharmaceutical Education and Research. 2020;54(3s):s512-s520. 